\title{
Numerical analysis of influence of ship hull form modification on ship resistance and propulsion characteristics
}

\author{
Part III \\ Influence of hull form modification \\ on screw propeller efficiency
}

\author{
Tomasz Abramowski, Ph. D. \\ Katarzyna Żelazny, D.Sc., Eng. \\ Tadeusz Szelangiewicz, Prof. \\ West Pomeranian University of Technology, Szczecin
}

\begin{abstract}
After signing ship building contract shipyard's design office orders performance of ship resistance and propulsion model tests aimed at, apart from resistance measurements, also determination of ship speed, propeller rotational speed and propulsion engine power for the designed ship, as well as improvement of its hull form, if necessary. Range of ship hull modifications is practically very limited due to cost and time reasons. Hence numerical methods, mainly CFD ones are more and more often used for such tests. In this paper consisted of three parts, are presented results of numerical calculations of hull resistance, wake and efficiency of propeller operating in non-homogenous velocity field, performed for research on 18 hull versions of B573 ship designed and built by Szczecin Nowa Shipyard.
\end{abstract}

Keywords: ship hull geometry, numerical (computational) fluid dynamics (CFD), resistance, wake current, propeller efficiency

\section{SHIP PROPULSION EFFICIENCY}

In design practice the overall propulsive efciency is presented in the form of the product of efficiency components [1]:

$$
\eta=\eta_{\mathrm{HT}} \eta_{0} \eta_{\mathrm{RT}} \eta_{\mathrm{S}} \eta_{\mathrm{G}}
$$

or:

$$
\eta=\eta_{\mathrm{HQ}} \eta_{0} \eta_{\mathrm{RQ}} \eta_{\mathrm{S}} \eta_{\mathrm{G}}
$$

where:

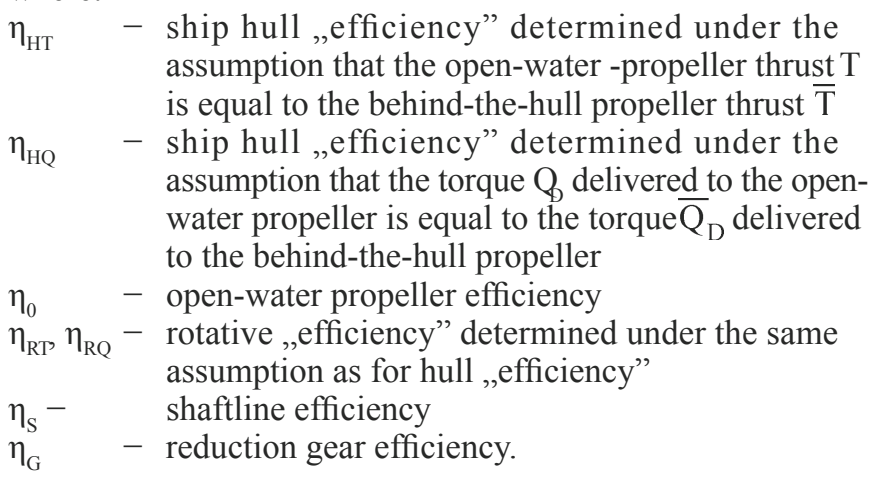

The two components: $\eta_{\mathrm{s}}$ and $\eta_{\mathrm{G}}$ are mechanical efficiencies, not associated with water flow around ship' s hull, propeller and rudder. Therefore they do not affect ship's hull-propeller - rudder collaboration.

The first three components, being of hydrodynamic character, are decisive of overall propulsive efficiency, and basin model tests to be performed have to provide ship designer with information necessary a.o. to determine their values.

However worth paying attention is that :

- for determining $\eta_{H}$ and $\eta_{R}$ are used averaged values obtained from measurements taken during model basin tests (the wake current velocity field measured during model tests is easily converted to ship scale, that not always brings good results)

- the presented efficiency components do not contain other factors affecting the overall propulsive efficiency (influence of some of them can be determined by conducting multiple model basin tests e.g. for various versions of ship hull stern part)

- in the above presented formulas is contained the openwater-propeller efficiency $\eta_{0}$ determined for the screw propeller operating in homogenous water velocity field without presence of ship hull, whereas the behind-the-hull screw propeller operates in a very non-homogenous velocity field, and the coefficients $\eta_{H}, \eta_{R}$ do not reflect essence of the problem, 
- also, in the above presented formulas ef fects of rudder, especially streamline one, which may increase efficiency of screw propeller, are lacking

- the above presented formulas do not contain information on mutual location of screw propeller and blade rudder relative to ship stern, and on its impact on propulsive efficiency.

The above described way of the determining of propulsive efficiency contains certain ambiguities (e.g. those associated with wake-fraction determining) hence in the publications [23] it is postulated to introduce the coefficients connected with the behind-the-hull propeller efficiency:

$$
\begin{gathered}
\xi_{\mathrm{Q}}=\frac{\mathrm{Q}_{\mathrm{D}}}{\overline{\mathrm{Q}}_{\mathrm{D}}} \\
\xi_{\mathrm{T}}=\frac{\overline{\mathrm{T}}}{\mathrm{T}}
\end{gathered}
$$

called the torque modifier and thrust modifier, respectively.

Regardless of that which approach would be applied to determining the ship propulsive efficiency, it is rational to determine thrust and torque of the behind- the-hull screw propeller as well as its efficiency in non-homogenous water velocity field for mean working point equivalent to mean service speed of ship (the mean statistical ship speed was discussed in [4]).

To determine real propulsive efficiency of ship or also efficiency of propeller operating behind the hull in nonhomogenous velocity field, is possible by using CFD techniques. Hence in this part of the paper are presented results of numerical computation of efficiency of screw propeller operating in nonhomogenous water velocity field, performed for 18 modified hull versions of B 573 ship. For the computations use is made of the results of numerical calculation of wake currents, presented in the part II of the paper.

\section{NUMERICAL CALCULATION OF HYDRODYNAMIC CHARACTERISTICS OF SCREW PROPELLER}

Before the calculations of efficiency of a screw propeller operating in non-homogenous velocity field, hydrodynamic characteristics of a store screw propeller used to propulsion model tests of B 573 ship [5], were calculated (the screw geometry is presented in Fig. 30).

The calculations of the store screw propeller were performed in the scale 1:1 by modelling the flow with the use of RANS equations and RNG k -epsilon model was applied to turbulence phenomena. Boundary layer was modeled by means of standard flow approximating functions, where the parameter $\mathrm{y}^{+}=50$.

To discretize domains a numerical non-structural network of prismatic elements within boundary layer (Fig. 31), which was further adjusted to polyhedral elements (Fig. 32). was applied. The non-structural network was elaborated by using Gambit system; and the conversion was performed by using Fluent system. All screw propeller blades were modeled, that demands on one hand a greater computer capacity, but on the other hand makes non-stationary calculations of screw propeller with taking into account non-design conditions, possible.

Calculation time step was equal to $0.00012 \mathrm{~s}$, that was equivalent to about $1^{\circ}$ of one screw-propeller revolution at its rotational speed of $17 \mathrm{rps}$. Two complete screw-propeller revolutions were covered by the calculations, hence the total time of the calculated flow was equal to $0.0864 \mathrm{~s}$.

\section{Results of numerical calculations:}

pressure distribution on screw propeller blades is presented in Fig. 33 and 34

streamlines - in Fig. 35

- total velocity profiles - in Fig. 36

- hydrodynamic characteristics - in Fig. $37 \div 39$

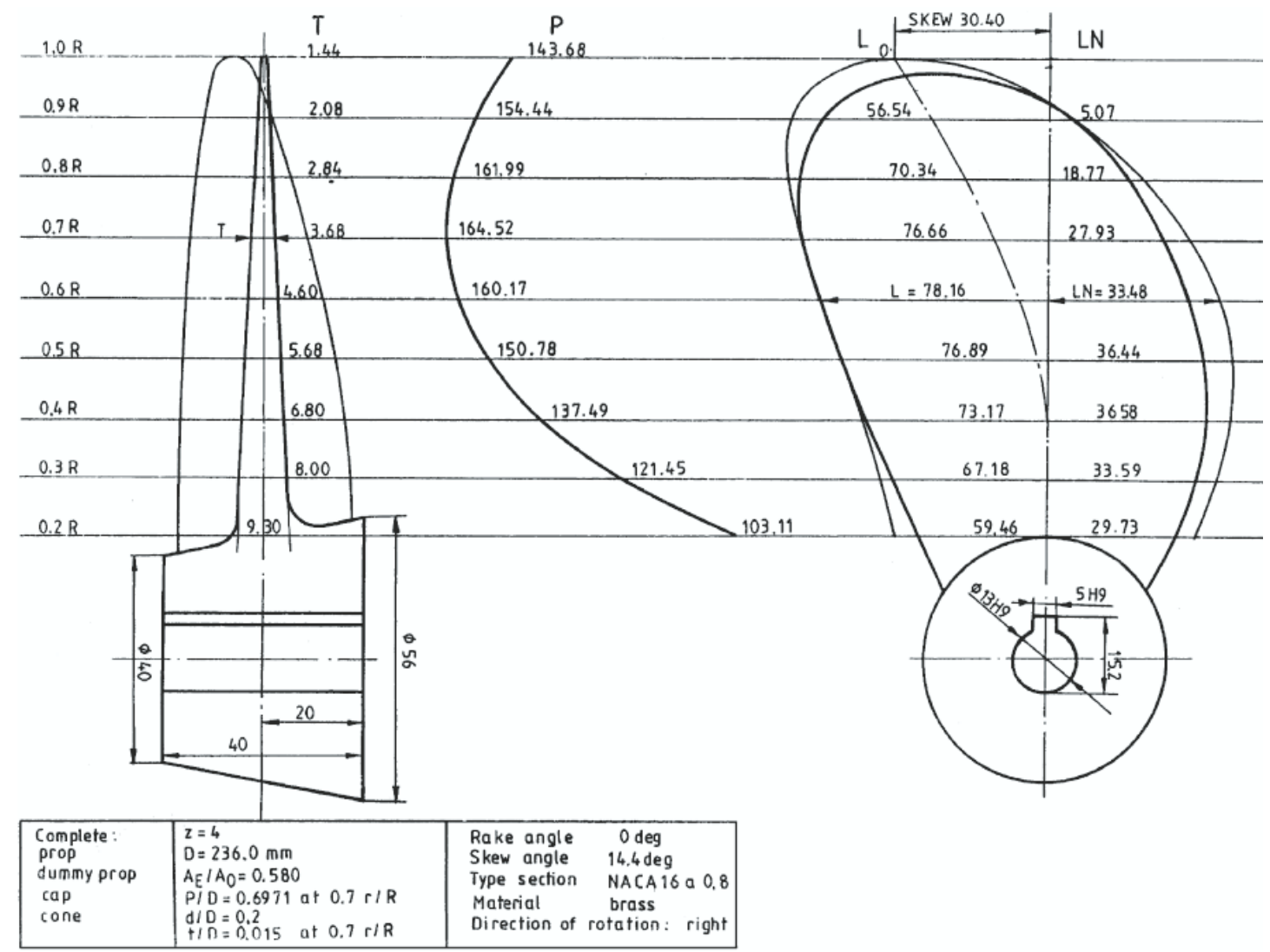

Fig. 30. Geometry of the store screw propeller No. P 355 [5] 


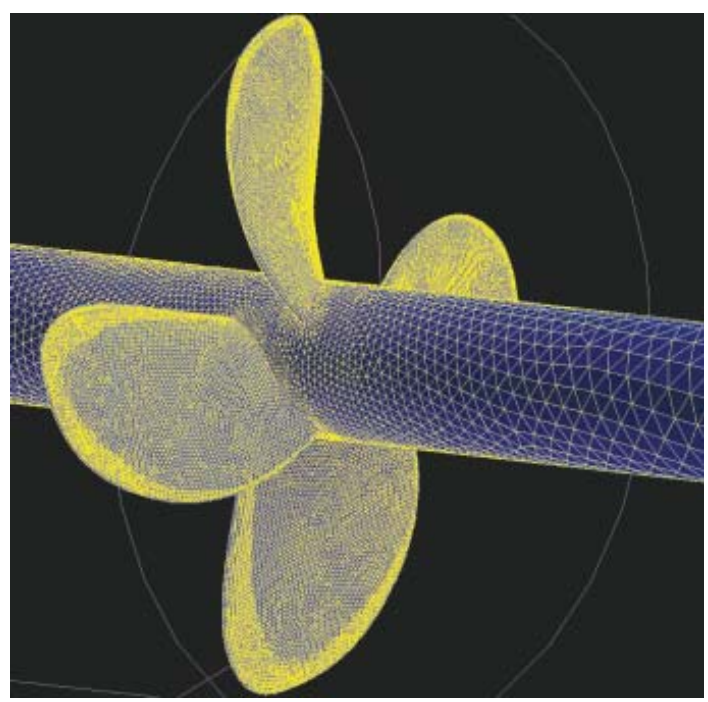

Fig. 31. Non-structural network of elements before conversion

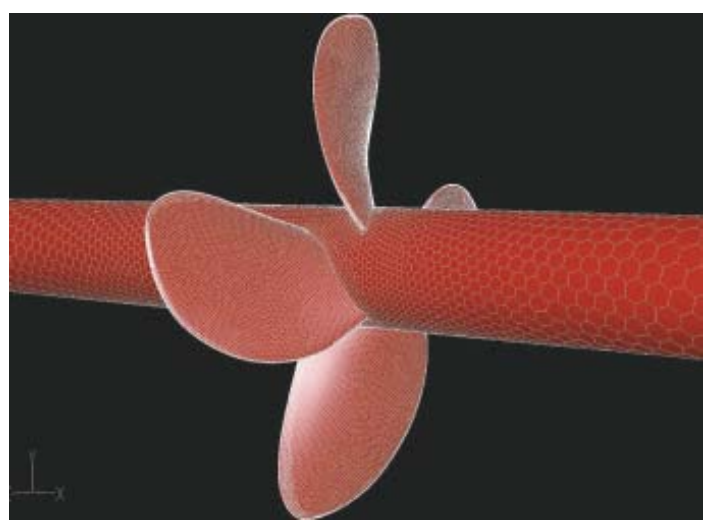

Fig. 32. Polyhedral network of elements converted from non-structural one

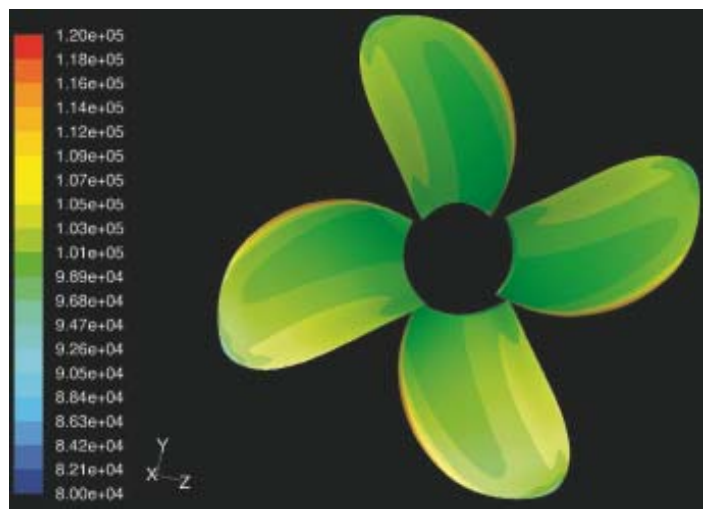

Fig. 33. Pressure distribution on driving face of screw propeller blades, the advance ratio $J=0.4$

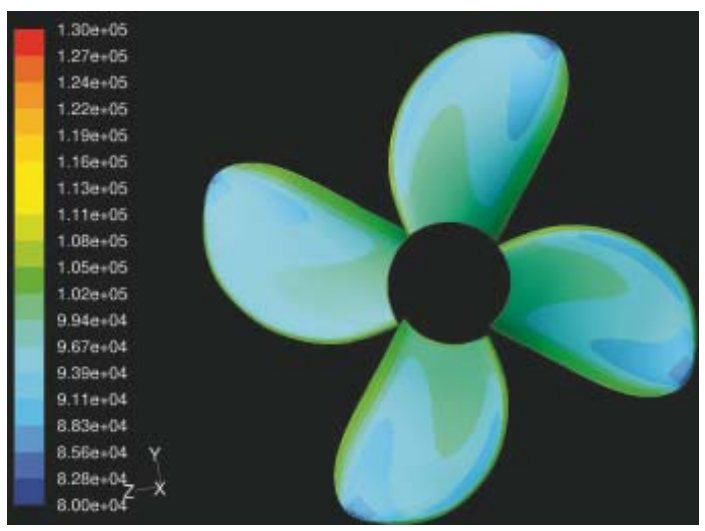

Fig. 34. Pressure distribution on drag surface of screw propeller blades, the advance ratio $J=0.4$

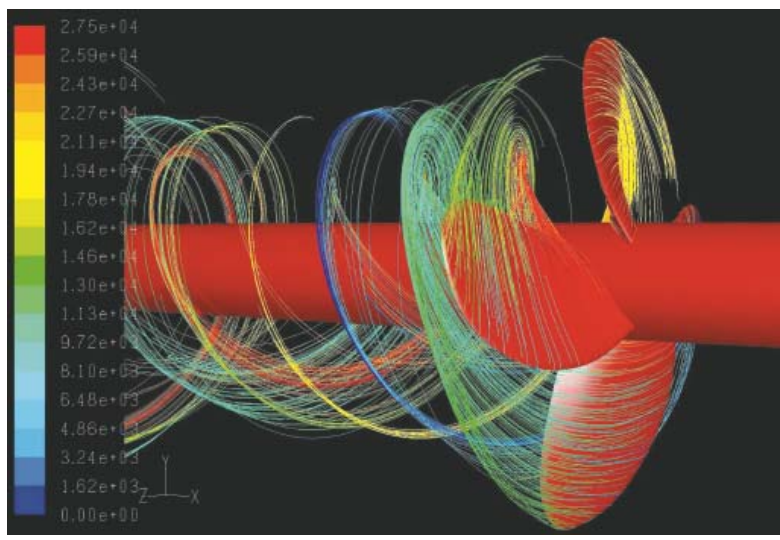

Fig. 35. Streamlines behind the screw propeller

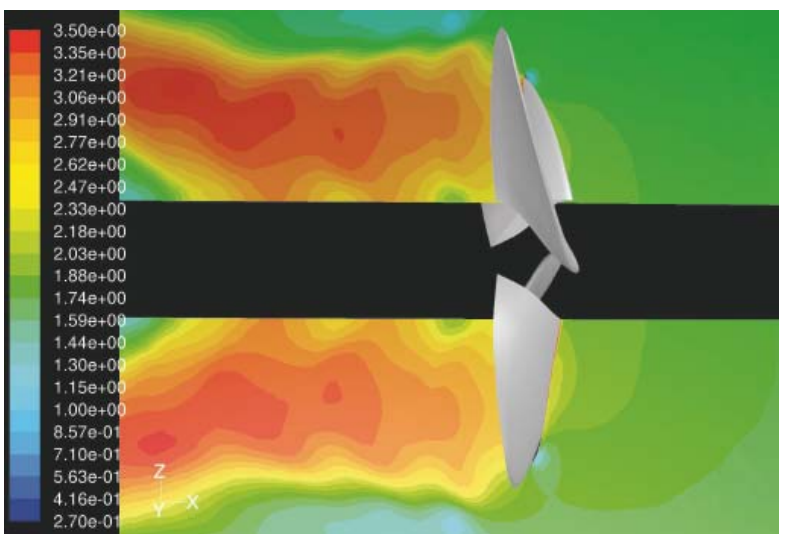

Fig. 36. Total velocity profiles

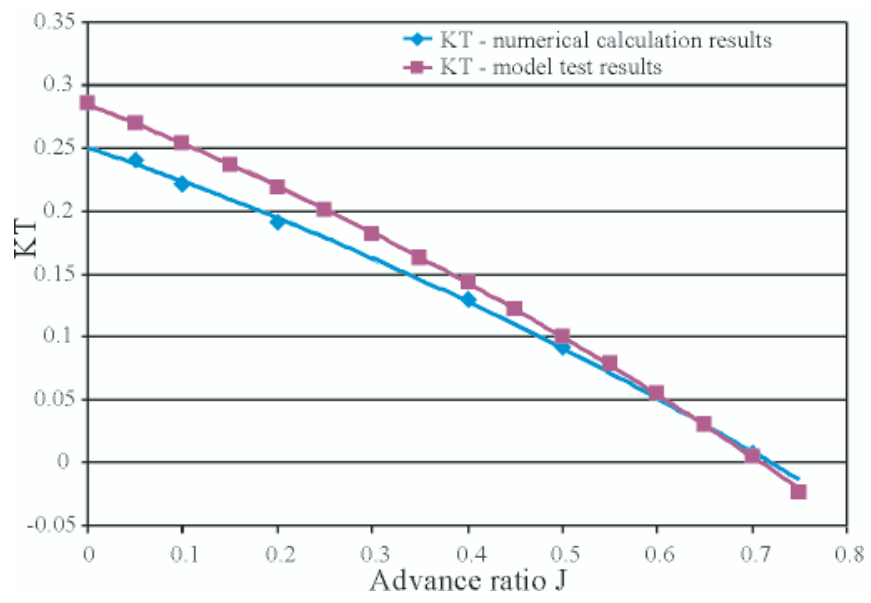

Fig. 37. Calculation results of the thrust coefficient $K T$ compared with model test results [5]

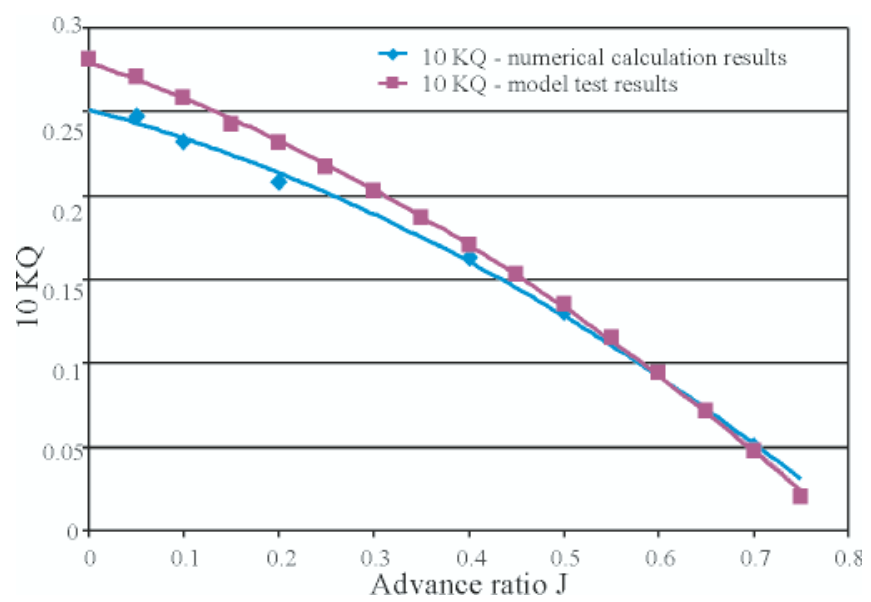

Fig. 38. Calculation results of the torque coeficient $K Q$ compared with model test results [5] 


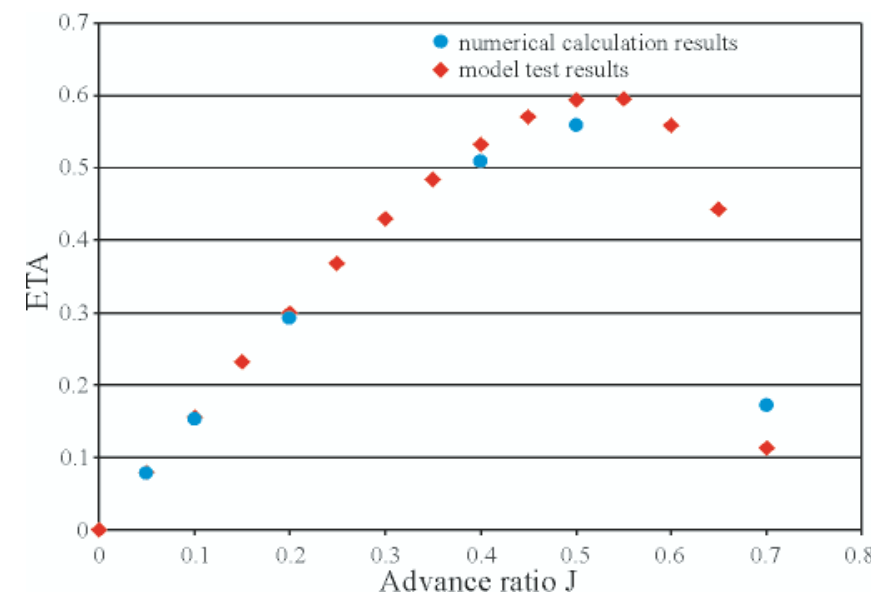

Fig. 39. Calculation results of the screw propeller efficiency eta compared with model test results [5]

\section{MEAN EFFICIENCY OF FINAL SCREW PROPELLER IN NON-HOMOGENOUS WAKE CURRENT VELOCITY FIELD}

The modification of B 573 ship's hull form was aimed at investigations of influence of the introduced hull form changes on the ship's resistance, wake current and screw propeller efficiency. The obtained distributions of wake current were used for determining the mean efficiency of the final screw propeller for B 573 ship.

The numerical calculations were performed for the final screw propeller of B 573 ship [6] in the same way as for the store screw propeller, however in the case of the final screw propellepr the water velocity field (in which axial and circumferential components were taken into account), calculated for each of the modified version of the ship's hull form, was introduced. The final results of the analyses are presented in Fig. 40 in the form of the mean efficiency of screw propeller operating in non-homogenous wake current field. In the figure the mean efficiency values are shown for particular versions (variants) of the modified ship hull forms in compliance withTab. 1. The case 0 is calculated for the screw propeller operating in the nonhomogenous flow velocity field measured during model tests of the B 573 ship hull (of non-modified form).The continuous line (marked red) stands for the maximum efficiency of the final open-water screw propeller operating in homogenous flow velocity field.

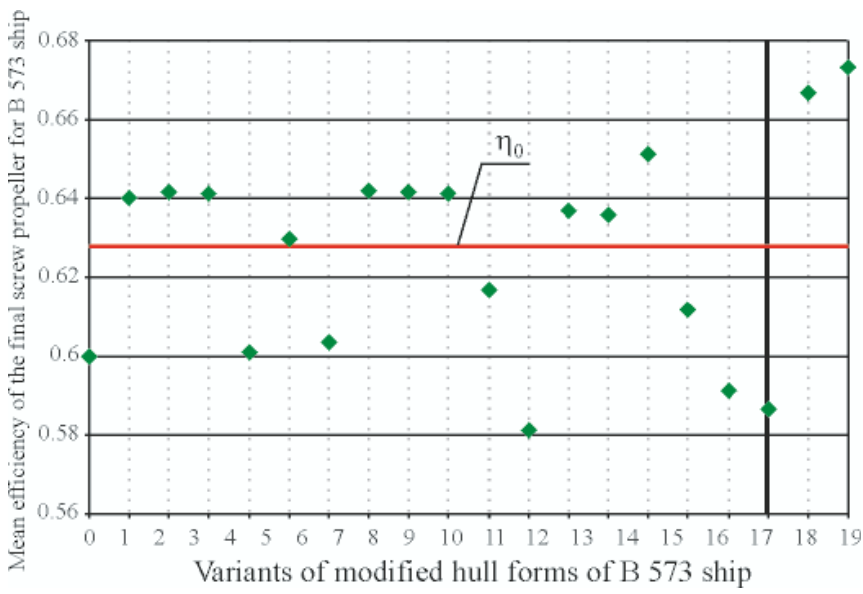

Fig. 40. Mean efficiency of B 573 ship's screw propeller operating in nonhomogenous wake current field, where: $\boldsymbol{\eta}_{0}$ - maximum efficiency of the final screw propeller in homogenous flow velocity field, variant $\mathbf{0}$ - original hull form (without modification) in wake current velocity field measured during model tests, variant $\mathbf{1 8}$ - symmetrical hull form with manually modified stern part

\section{FINAL CONCLUSIONS}

The tests performed in advance each of the main calculations demostrated a good conformity of CFD calculations to model tests. Certain observed differences may result from various causes (some of them were discussed in the Part I of this work). The differences in hydrodynamic characteristics of the store screw propeller could also result from some, out of all necessary to elaborate a 3D model and numerical network, geometrical quantities lacking in [5].Therefore it is not certain whether the computational model of the store screw propeller has represented exactly its real features. In the case of the final screw propeller there was no available results of model tests or other calculations to make verification of the CFD computation results possible.

- Numerical calculations of the mean efficiency of screw propeller for $18^{\text {th }}$ hull version of B 573 ship (Fig. 40) demonstrated that small modifications can have either favourable or unfavourable effect onto efficiency. Especially favourable effect in the form of elevated efficiency was obtained by using manual modification of only stern part of the ship's hull ( $18^{\text {th }}$ variant, Fig. 40 ). It means that by suitable modelling hull form in its stern part only it is possible to make flow velocity field before the propeller more favourable from the point of view of efficiency.

- Mean values of screw propeller efficiency for wake currents corresponding to particular versions of ship hull were calculated for the same final screw propellerInvestigations on searching for optimum screw propeller geometry for each of the ship's hull versions, are under way.

Numerical methods based on the CFD provide even greater possibilities, e.g. investigations on propulsive efficiency of the whole system composed of ship hull, screw propeller and streamline rudder, that would make performing a more advanced optimization of ship propulsion system, possible.

\section{BIBLIOGRAPHY}

1. Dudziak J.: Ship theory (in Polish). 2nd Edition, Fundacja Promocji Przemysłu Okrętowego i Gospodarki Morskiej (Fundation for Promotion of Ship Industry and Maritime Economy), Gdańsk 2008

2. Jarzyna H.: Some Consequences of the Analytical Design of the Ship Propellers. Proceedings of the Conference on Advances in Propeller Research and Design, PAN, IMP (Institute of Fluid Flow Machinery, Polish Academy of Sciences), Gdańsk 1981

3. Jarzyna H., Koronowicz T., Szantyr J.: Design of Marine Propellers. Selected Problems. Zakład Narodowy im. Ossolińskich, Wydawnictwo PAN (Publishing House of Polish Academy of Sciences), Wrocław 1996

4. Szelangiewicz T., Żelazny K.: Calculation of the mean longterm service speed of transport ship, Part I - Polish Maritime Research (PMR), No. 4/2006, Part II - PMR No. 1/2007, Part III - PMR No. 2/2007

5. Syrocki W.: Ship B 573 -Results of Model Tests. Ship Design and Research Centre, Technical Report No. RH-96/T-023A, Gdańsk 1995

6. Syrocki W.: Ship B 573 - Final Design of Propeller. Ship Design and Research Centre, Technical Report No. RH-95/T-115 A, Gdańsk 1995.

\section{CONTACT WITH THE AUTHORS}

Tomasz Abramowski, Ph. D.

Katarzyna Żelazny, D. Sc.

Tadeusz Szelangiewicz, Prof.

West Pomeranian University of Technology, Szczecin

Faculty of Marine Technology

Al. Piastów 41

71-065 Szczecin, POLAND

e-mail: tadeusz.szelangiewicz@ps.pl 